\title{
Perioperative Analgesic Effects of Preemptive Ultrasound-Guided Subcostal Transversus Abdominis Plane Block for Percutaneous Nephrolithotomy: A Prospective, Randomized Trial
}

\author{
Aylin Özdilek, MD, ${ }^{1}$ Çiğdem Akyol Beyoğlu, MD, Çetin Demirdağ, MD, ${ }^{2}$ Öznur Şen, ${ }^{3}$ \\ Şafak Emre Erbabacan, ${ }^{1}$ Birsel Ekici, MD, ${ }^{1}$ Fatiş Altindaş, ${ }^{1}$ and Güniz Meyanci Köksal ${ }^{1}$
}

\begin{abstract}
Background and Objectives: Percutaneous nephrolithotomy (PCNL) is a minimally invasive procedure for removing kidney stones, but patients still suffer from moderate postoperative pain. The aim of this study is to evaluate the perioperative analgesic effect of ultrasound-guided subcostal transversus abdominis plane (TAP) block performed before PCNL procedure.

Materials and Methods: Patients scheduled for elective PCNL were randomized into two groups: Group TAP and Group IV. General anesthesia was induced with propofol, fentanyl, and rocuronium and maintained with sevoflurane, fentanyl, and rocuronium. Unilateral ultrasound-guided TAP block was performed with total of $30 \mathrm{~mL}$ volume of local anesthetic solution $(20 \mathrm{~mL}$ bupivacaine $0.125 \%$ plus $10 \mathrm{~mL}$ lidocaine $1 \%$ ) after intubation but before surgery to the Group TAP patients. Paracetamol $1 \mathrm{~g}$ was given to the Group IV. Tramadol $100 \mathrm{mg}$ and morphine IV-patient-controlled analgesia were applied to both groups. Perioperative fentanyl consumption, postoperative verbal analog scale (VAS), morphine consumption, and additional analgesic drug requirement were assessed. Chi square with Yates correction and Mann-Whitney $U$ tests were used for statistical analysis. Results: Eighty patients were assessed for enrollment. One patient developed septicemia at the recovery room so data of 79 patients were collected for statistical analysis. Total morphine consumption at 48th hour after the surgery was lower at Group TAP $(p=0.022)$. Perioperative fentanyl consumption was lower at Group TAP $(p<0.001)$. Additional analgesic requirement and VAS were comparable between groups.

Conclusions: Preemptive unilateral ultrasound-guided subcostal TAP block decreases perioperative fentanyl and postoperative total morphine consumption in PCNL patients compared to IV analgesic management.
\end{abstract}

Keywords: percutaneous nephrolithotomy, subcostal transversus abdominis plane block, analgesia, morphine, fentanyl, ultrasound

\section{Introduction}

$\mathbf{P}$ ERCUtaneous nephrolithotomy (PCNL) Is a minimally invasive, effective, and well-defined procedure recommended as a first choice of treatment for kidney stones larger than $20 \mathrm{~mm} .{ }^{1}$ Despite the small skin incision patients suffer from postoperative pain due to visceral pain, intercostal nerve injury, distension of the renal capsule and pelvicaliceal system, and irritation of nephrostomy tubes. ${ }^{2}$ To decrease the postoperative pain, techniques such as peri-tubal local anesthetic infiltration, paravertebral block (PVB), epidural analgesia, IV analgesic drugs, and tubeless or smallbore puncture procedures are used in PCNL patients. ${ }^{3-5}$ Intravenous narcotics can cause nausea, vomiting, ileus, sedation, respiratory depression, and opioid abuse. ${ }^{6}$ Thus, regional analgesic techniques are widely used for all kinds of surgeries as a component of opioid-sparing multimodal analgesia.

Transversus abdominis plane (TAP) block originally described by Rafi $^{7}$ provides analgesia by blocking the 7 th to 11th intercostal nerves (T7-T11), the subcostal nerve (T12),

Departments of ${ }^{1}$ Anesthesiology and Reanimation and ${ }^{2}$ Urology, Cerrahpasa Medical Faculty, Istanbul University-Cerrahpasa, Istanbul, Turkey.

${ }^{3}$ Department of Anesthesiology and Reanimation, Haseki Education and Research Hospital, Istanbul, Turkey.

Interim data from this work were presented at the Euroanesthesia 2018 in Copenhagen, Denmark, June 2-4, 2018. 
ilioinguinal nerve, and iliohypogastric nerve (L1-L2). After introducing ultrasound to the anesthesia practice, the location of intervention changed. Subsequently subcostal TAP block was described by Hebbard ${ }^{8}$ and since then used mainly for upper abdominal surgeries. ${ }^{9-13}$ The extent of the sensory block seen with subcostal TAP block is between T6-T10 on the abdominal wall. ${ }^{14}$

The aim of this study is to evaluate the perioperative analgesic effect of ultrasound-guided subcostal TAP block performed before PCNL procedure.

\section{Materials and Methods}

\section{Study design}

This prospective, randomized clinical trial was conducted at the Istanbul University-Cerrahpasa, Cerrahpasa Medical Faculty Hospital from October 2015 to September 2017. The study was conducted in accordance with Declaration of Helsinki, approved by Ethics Committee of Haseki Education and Research Hospital (approval no. 186/28.01.2015). Written informed consent was obtained from all participants.

The study was registered on clinicaltrials.gov (NCT03454139).

\section{Participants}

Eighty patients enrolled for PCNL surgery with American Society of Anesthesiologists (ASA) score of I-III status and age of 18 to 70 were assessed for enrollment. One patient enrolled for Group TAP developed septicemia at the recovery room hence the patient was excluded from the study. Data of 79 patients were collected for statistical analysis.

Patients with chronic pain, on opioid or other analgesic drugs, body mass index (BMI) higher than 40, allergies for drugs used in the study, chronic renal failure receiving dialysis, and patients who were converted to open surgery were excluded from the study.

\section{Randomization}

Patients were randomly assigned to either Group TAP (unilateral ultrasound-guided subcostal TAP block) or Group IV (IV analgesic treatment) using a randomization scheme generated by randomization.com (www.randomization.com). The patients, anesthesiologists responsible for patients' treatment during the operation, outcome assessor (Ç.A.B.), and data analyzer were blinded to group assignment. Surgeon performing the surgery (C..D.) and anesthesiologist administrating the TAP blocks (A.Ö.) were not blinded. Anesthesiologists responsible for patients' treatment during the operation were asked to leave the operating room for 10 minutes after intubation for each patient to be blinded to the study group. A patch was placed covering the actual or supposed puncture site and removed at 48th hour, after the study was over.

\section{Anesthesia}

General anesthesia was induced with midazolam $2 \mathrm{mg}$, propofol $2 \mathrm{mg} / \mathrm{kg}$, fentanyl $1 \mathrm{mcgr} / \mathrm{kg}$, and rocuronium $0.6 \mathrm{mg} / \mathrm{kg}$ and maintained with sevoflurane $2 \%$ in $40 \%: 60 \%$ oxygen/air mixture. Fentanyl $0.5 \mathrm{mcgr} / \mathrm{kg}$ was added if mean arterial pressure and/or heart rate increases more than $20 \%$ from the baseline values. Ondansetron $4 \mathrm{mg}$ was adminis- tered to all patients 20 minutes before the end of the surgery. Paracetamol $1000 \mathrm{mg} / 100 \mathrm{~mL}$ was given every 8 hours to all patients for postoperative analgesia.

\section{Study groups}

Group TAP. After anesthesia induction ultrasound guided subcostal TAP block was performed ipsilateral of the kidney stone by the same anesthesiologist (A.Ö.). The $12 \mathrm{MHz}$ linear probe of ultrasound system (MyLab Five, Esaote, Holland) was placed under the costal margin near the xyphoid and rectus abdominis; external oblique, internal oblique, and transversus abdominis muscles were identified. Following full aseptic precautions, a 21-gauge needle (Stimuplex A, 21gauge, $100 \mathrm{~mm}$; Braun, Germany) was advanced from medial to lateral, between internal oblique muscle fascia and transversus abdominis muscle fascia using an in-plane technique. Needle location was confirmed by injecting $1 \mathrm{~mL}$ of $0.9 \%$ saline. A composition of $10 \mathrm{~mL}$ lidocaine $1 \%$, plus $20 \mathrm{~mL}$ bupivacaine $0.125 \%$, total of $30 \mathrm{~mL}$ of local anesthetic mixture was administered into the area between internal oblique muscle fascia and transversus abdominis muscle fascia. After performing the block, the patient was positioned to lithotomy position, and an open-ended ureteric catheter was advanced up to the kidney with the stone. Subsequently, the patient was turned to prone position, and the PCNL surgery was performed. Tramadol $100 \mathrm{mg}$ was administrated 20 minutes before the extubation. Morphine IV patient-controlled analgesia (PCA) (bolus $1 \mathrm{mg}$ and 10 minutes lockout time) was started for postoperative pain management immediately after the extubation.

Group IV. Regional analgesia was not administered to these patients. After anesthesia induction, the patient was positioned to lithotomy position, and an open-ended ureteric catheter was advanced up to the kidney with the stone. Then the patient was turned to prone position, and the PCNL surgery was performed. Paracetamol $1000 \mathrm{mg} / 100 \mathrm{~mL}$ and Tramadol $100 \mathrm{mg}$ were administered 20 minutes before the extubation for postoperative analgesia. Morphine IV PCA (bolus $1 \mathrm{mg}$ and 10 minutes lockout time) was started for postoperative pain management immediately after the extubation.

\section{Surgical technique}

All operations were performed by the same surgical team (Ç.D.) using a standardized technique. Under general anesthesia, all patients underwent an open-ended ureteral catheterization (Boston Scientific-microvasive, Watertown, MA) in the lithotomy position with cystoscopy, and the success of the procedure was checked with Biplanar C-arm fluoroscopy (Siemens-Siremobil Compact). Then, patients were placed in prone position. When needed, Biplanar C-arm fluoroscopy was performed to visualize the pelvicaliceal system by opaque or air through the open-ended ureteral catheter. With the help of 30- and 90-degree movements of the biplanar C-arm fluoroscopy, the appropriate calix collecting system was entered with the 18-gauge needle. Once the guidewire was easily advanced to the ureter and the safety wire was inserted with a double lumen catheter, the nephrostomy tract was dilated with a balloon dilator and a 30F Amplatz sheath was placed into the kidney collector system. The rigid nephroscope (26F Storz nephroscope) was used to visualize the 
stones. Without breaking the stones of appropriate size, large stones were disintegrated by means of pneumatic lithotriptor and taken out by forceps. The pelvic and lower caliceal stones were easily accessed and removed. At the end of the procedure, $14 \mathrm{~F}$ Malecot nephrostomy tube was placed in the collecting system.

\section{Outcomes}

Perioperative fentanyl consumption and total morphine consumption, verbal analog scale (VAS), and additional analgesic drug requirements were assessed at 0th minute, 30th minute, 1st hour, 2nd hour, 3rd hour, 12th hour, 24th hour, and 48th hour after the surgery.

Verbal analog scale. Patients were asked to rate their pain between 0 and 10 , as 0 means "no pain," 1 to 3 means "mild pain," 4 to 6 means "moderate pain," 7 to 9 means "severe pain," and 10 means "worst imaginable pain." Patients were educated in using VAS the day before the surgery, during the preanesthetic evaluation.

Primary outcome of our study was total morphine consumption at 48th hour after the surgery. Secondary outcomes were perioperative fentanyl consumption, postoperative VAS, and additional analgesic drug requirement.

History of extracorporeal shockwave lithotripsy, PCNL, or open renal surgeries was noted. Age, gender, weight, height, BMI, ASA score, size of the stone/stones (centimetersquare), duration of surgery (minutes), type of surgical tract access (subcostal or intercostal), number of access tracts (single or multiple), localization of stone/stones (upper calix, middle calix, lower calix, pelvis, staghorn, multiple), duration of nephrostomy tube placement, and immediate stone free outcomes were recorded.

All postoperative assessments were made by the same anesthesiologist (Ç.A.B.) who was blinded to the study group.

\section{Statistics}

The sample size calculation was based on preliminary study results. Assuming a power of $80 \%$ and a level of significance of $5 \%$, it was estimated that at least 34 patients would be required for each group.

Normality of data was evaluated by the Shapiro-Wilk test, Q-Q plot, box plot, and histogram. Results are expressed as mean \pm standard deviation (for normal data), median, range (for non-normal data), and frequencies and percentages (for categorical data). The comparison of groups was performed with the independent samples $t$-test (for normal data) and with the Mann-Whitney $U$ test (for non-normal data). Spearman correlation test was used for correlation between quantitative variables. Nominal and categorical variables were compared with the chi square test with Yates correction and with the Fisher's exact probability test. $p$ Values (twotailed) $<0.05$ were considered significant. Data were analyzed using the software package NCSS 10 (2015; Kaysville, UT).

\section{Results}

Demographic and surgical data of the patients are included in Table 1. Number of male patients was higher in Group IV compared to Group TAP ( $p=0.006)$ (Table 1).
Total morphine consumption at 48th hour after the operation was lower in Group TAP compared to Group IV $(p=0.02)$ (Table 2). Perioperative fentanyl consumption was significantly higher in Group IV compared to Group TAP $(p<0.001)$ (Table 2).

Additional analgesic requirement and VAS were comparable between the groups at all time points (Table 2). The number of patients with VAS values equal to or higher than 4 was not significantly different between the groups (Fig. 1).

No complications related to TAP block procedure were observed.

The duration of nephrostomy tube placements was similar and was 2.1 days for both groups $(p>0.05)$. In addition, immediate stone-free outcomes were similar and $78.2 \% \mathrm{vs}$ $79.1 \%$ for Group TAP and Group IV, respectively $(p>0.05)$.

\section{Discussion}

According to our literature search, our study is the first one investigating subcostal TAP block's analgesic effect in PCNL surgeries. We compared subcostal TAP block with standard IV analgesic management for PCNL patients.

Opioid epidemic is a growing problem, caused by liberal use of opioids for various indications. Opioids are effective analgesics for surgical pain, but when used perioperatively can cause nausea, vomiting, ileus, sedation, respiratory depression, opioid abuse, and opioid-induced hyperalgesia defined as a worsening of pain despite the use of high dose opioids. ${ }^{15}$ Multimodal approach for postoperative analgesia, including regional techniques and nonopioid drugs, is preferred to avoid side effects of the opioids.

TAP block is effective on abdominal skin, muscles, and parietal peritoneum pain, but cannot block visceral pain. ${ }^{15}$ For that reason, we applied multimodal analgesia (TAP block, paracetamol, IV morphine PCA, and tramadol) to our patients.

We hypothesized that multimodal approach, including preemptive TAP block and systemic analgesic drugs, will provide adequate pain control for PCNL patients and will reduce perioperative opioid consumption. Carney and colleagues ${ }^{16}$ showed posterior extension after anterior subcostal TAP block in their study investigating the spread of local anesthetic solution in volunteers. So, we performed the TAP block following the anesthesia induction, before the start of the surgery, and then the patient was positioned to lithotomy position. The aim was to facilitate the spread of local anesthetic solution more posteriorly, while open-ended ureteral catheter was inserted by the surgeon.

We found that total morphine consumption at postoperative 48th hour was lower in Group TAP compared to Group IV. Similarly, in studies investigating TAP block efficacy in laparoscopic cholecystectomy patients, postoperative tramadol PCA consumption was found to be lower in TAP block groups compared to the control groups. ${ }^{12,13,17,18}$

Perioperative fentanyl consumption was significantly higher in Group IV compared to Group TAP in our study. Similar results were found in a study which compared oblique subcostal TAP block with bupivacaine to placebo oblique subcostal TAP block in laparoscopic cholecystectomy: intraoperative opioid consumption was lower in bupivacaineTAP block group. ${ }^{19}$ Amr et al. ${ }^{20}$ reported that intraoperative 
Table 1. Demographic and Surgical Data of the Patients

\begin{tabular}{|c|c|c|c|}
\hline Variables & $\begin{array}{c}\text { Group TAP } \\
\mathrm{n}=39\end{array}$ & $\begin{array}{c}\text { Group } I V \\
\mathrm{n}=40\end{array}$ & $\mathrm{p}$ \\
\hline Age (years), mean \pm SD & $46.5 \pm 12.2$ & $45.9 \pm 11.5$ & $0.83^{\mathrm{a}}$ \\
\hline Gender F/M, $n$ & $18 / 21$ & $6 / 34$ & 0.006 \\
\hline Height $(\mathrm{cm})$, mean \pm SD & $167.4 \pm 7.4$ & $170.2 \pm 8.2$ & $0.12^{\mathrm{a}}$ \\
\hline Weight $(\mathrm{kg})$, median (min.-max.) & $79.6(50-120)$ & $82.9(53-120)$ & $0.21^{\mathrm{c}}$ \\
\hline BMI, median (min.-max.) & $29(21-39)$ & $28.7(19-39)$ & $0.95^{\mathrm{c}}$ \\
\hline Duration of surgery (minute), median (min.-max.) & $180(105-270)$ & $167.5(85-445)$ & $0.23^{\mathrm{c}}$ \\
\hline Stone size $\left(\mathrm{cm}^{2}\right)$, median (min.-max.) & $4(1-10)$ & $3.9(1.3-10)$ & $0.76^{\mathrm{c}}$ \\
\hline \multicolumn{4}{|l|}{ ASA, $n$} \\
\hline 1 & 21 & 21 & \multirow[t]{3}{*}{$0.99^{\mathrm{d}}$} \\
\hline 2 & 17 & 18 & \\
\hline 3 & 1 & 1 & \\
\hline Previous SWL, $n$ & 4 & 3 & $1^{\mathrm{d}}$ \\
\hline Previous PCNL, $n$ & 2 & 4 & $0.68^{\mathrm{d}}$ \\
\hline Previous open renal surgery, $n$ & 4 & 3 & $0.71^{\mathrm{d}}$ \\
\hline \multicolumn{4}{|l|}{ Surgical tract access } \\
\hline Subcostal access, $n$ & 27 & 34 & \multirow[t]{2}{*}{$0.16^{\mathrm{b}}$} \\
\hline Intercostal access, $n$ & 12 & 6 & \\
\hline \multicolumn{4}{|l|}{ Number of access tract, $n$} \\
\hline Single access tract & 36 & 35 & \multirow[t]{2}{*}{$0.71^{\mathrm{d}}$} \\
\hline Multiple access tracts & 3 & 5 & \\
\hline \multicolumn{4}{|l|}{ Localization of stone/stones, $n$} \\
\hline Upper calix & 2 & 0 & \multirow{6}{*}{$0.67^{\mathrm{d}}$} \\
\hline Middle calix & 2 & 1 & \\
\hline Lower calix & 8 & 6 & \\
\hline Pelvis & 8 & 9 & \\
\hline Staghorn & 2 & 2 & \\
\hline Multiple & 17 & 22 & \\
\hline
\end{tabular}

${ }^{\mathrm{a}}$ Independent samples $t$-test.

${ }^{\mathrm{b}}$ Chi square with Yates correction.

${ }^{c}$ Mann-Whitney $U$ test.

${ }^{\mathrm{d}}$ Fisher's exact test.

Boldface value indicates statistical significance.

ASA=American Society of Anesthesiologists; $\mathrm{BMI}=$ body mass index; $\mathrm{SWL}=$ extracorporeal shockwave lithotripsy; $\mathrm{F}=$ female; $\mathrm{IV}=$ intravenous; $\mathrm{M}=$ male; $\max .=$ maximum; $\min .=$ minimum; $n=$ number; $\mathrm{PCNL}=$ percutaneous nephrolithotomy; $\mathrm{SD}=\mathrm{standard}$ deviation; $\mathrm{TAP}=$ transversus abdominis plane.

fentanyl consumption significantly decreased in preincisional TAP block group compared to postincisional and sham TAP block groups for acute and chronic hysterectomy pain.

$\mathrm{PVB}$ is one of the oldest regional techniques used for thoracic and abdominal pain relief. Baldea and colleagues ${ }^{21}$ performed PVB before PCNL surgery and found that intraoperative fentanyl and total morphine consumptions and VAS scores were lower compared to placebo intervention. Borle and coworkers ${ }^{2}$ inserted paravertebral catheter for PCNL and found that intraoperative fentanyl requirement is higher in control group. Recent meta-analysis showed similar results favoring PVB for PCNL pain treatment. ${ }^{22}$

Erector spinae plane block (ESPB) is a newly described but widely studied block. Case reports showed significant pain relief after ESPB for postoperative PCNL pain or renal colic. ${ }^{23,24}$ Randomized controlled trials evaluating ESPB for PCNL found lower VAS, opioid and additional analgesic consumptions, and longer time to rescue analgesia compared to control groups. ${ }^{25,26}$

Quadratus lumborum block (QLB) is another abdominal wall block investigated for postoperative PCNL pain control. Randomized studies show that QLB reduces VAS and opioid consumption compared to intravenous analgesic regimens. ${ }^{27-29}$
These results show that regional blocks applied before or after the surgery are effective and are worth to be considered for multimodal analgesic regimes.

We found that VAS pain score was comparable between the groups at all time points. TAP block is widely investigated for laparoscopic cholecystectomy, and the results are conflicting. Some studies state that there is not a difference at VAS scores between IV and TAP block analgesic techniques, ${ }^{30}$ and some studies found that oblique subcostal TAP block is correlated with lower VAS scores after laparoscopic cholecystectomy. ${ }^{12,13,18,19}$ More studies are needed to determine the analgesic efficacy of TAP block for PCNL surgeries.

We initially hypothesized that subcostal TAP block will reduce VAS in PCNL patients. The number of patients with VAS equal to or higher than 4 was not significantly different between groups. An explanation for the absence of difference may be due to local anesthetic concentration or volume of solution we used at our study. Or some of the postoperative analgesic effect of preemptive TAP block may be lost during the surgery due to drug pharmacokinetics.

Şahin et al. ${ }^{31}$ compared 20 to $30 \mathrm{~mL}$ ultrasound-guided TAP block for laparoscopic cholecystectomy and found that intraoperative remifentanil consumption, VAS scores, and 
Table 2. Verbal Analog Scale and Analgesic REQUIREMENT OF PATIENTS

\begin{tabular}{|c|c|c|c|}
\hline $\begin{array}{l}\text { Variables median } \\
\text { (min.-max.) }\end{array}$ & $\begin{array}{c}\text { Group TAP } \\
\mathrm{n}=39\end{array}$ & $\begin{array}{c}\text { Group IV } \\
\mathrm{n}=40\end{array}$ & $\mathrm{p}$ \\
\hline Fentanyl, $\mathrm{mcg} / \mathrm{kg}$ & $1.5(1-6)$ & $2(1-4)$ & $<0.001^{\mathrm{a}}$ \\
\hline \multicolumn{4}{|l|}{ VAS, $n(\%)$} \\
\hline VAS $<40$ th minute & $32(82.1)$ & $31(77.5)$ & \multirow{3}{*}{$0.82^{\mathrm{b}}$} \\
\hline VAS $\geq 4$ 0th minute & 7 (17.9) & $9(22.5)$ & \\
\hline VAS $<4$ 30th minute & $29(74.4)$ & $26(66.7)$ & \\
\hline VAS $\geq 4$ 30th minute & $10(25.6)$ & $13(33.3)$ & \multirow[t]{2}{*}{$0.62^{\mathrm{b}}$} \\
\hline VAS $<41$ st hour & $33(84.6)$ & $35(87.5)$ & \\
\hline VAS $\geq 4$ st hour & $6(15.4)$ & $5(12.5)$ & \multirow[t]{2}{*}{$0.96^{\mathrm{b}}$} \\
\hline VAS $<4$ 2nd hour & $38(97.4$ & $38(95)$ & \\
\hline VAS $\geq 42$ nd hour & $1(2.6)$ & $2(5)$ & \multirow[t]{9}{*}{$1^{\mathrm{c}}$} \\
\hline VAS $<4$ 3rd hour & 39 (100) & $40(100)$ & \\
\hline VAS $\geq 43$ & 0 & 0 & \\
\hline VAS $<41$ & $39(100)$ & $40(100)$ & \\
\hline VAS $\geq 412$ th hour & 0 & 0 & \\
\hline VAS $<4$ 24th hour & $39(100)$ & $40(100)$ & \\
\hline VAS $\geq 4$ 24th hour & 0 & 0 & \\
\hline VAS $<4$ 48th hour & $39(100)$ & $40(100)$ & \\
\hline VAS $\geq 4$ 48th hour & 0 & 0 & \\
\hline \multicolumn{4}{|c|}{ Morphine PCA consumption (cumulative dose), mg } \\
\hline 0th minute & $0(0-1)$ & $0(0-2)$ & $0.75^{\mathrm{a}}$ \\
\hline 30 th $\mathrm{n}$ & $2(0-4)$ & $2(0-5)$ & $0.65^{\mathrm{a}}$ \\
\hline 1st ho & $3(1-7)$ & $3(0-10)$ & $0.77^{\mathrm{a}}$ \\
\hline 2nd ho & $5(1-12)$ & $5(1-16)$ & $0.86^{\mathrm{a}}$ \\
\hline $3 \mathrm{rc}$ & $8(1-15)$ & $8(1-21)$ & $0.89^{\mathrm{a}}$ \\
\hline 12 & $12(2-27)$ & $16.5(2-34)$ & $0.11^{\mathrm{a}}$ \\
\hline 24th hour & $18(2-49)$ & $22(3-42)$ & $0.052^{\mathrm{a}}$ \\
\hline 48th hour & $20(2-95)$ & $28.5(3-53)$ & $\mathbf{0 . 0 2 2}$ \\
\hline \multicolumn{4}{|c|}{ Additional analgesic requirement, $n$} \\
\hline Oth minute & 6 & 9 & $0.60^{\mathrm{b}}$ \\
\hline 30th minute & 10 & 15 & $0.37^{\mathrm{b}}$ \\
\hline 1st hour & 6 & 4 & $0.52^{\mathrm{c}}$ \\
\hline 2nd hour & 1 & 2 & $1^{\mathrm{c}}$ \\
\hline 3rd hour & 0 & 1 & $0.49^{\mathrm{c}}$ \\
\hline
\end{tabular}

${ }^{\text {a } M a n n-W h i t n e y ~} U$ test.

${ }^{\mathrm{b}}$ Chi square with Yates correction.

'Fisher's exact test.

Boldface values indicate statistical significance.

PCA $=$ patient-controlled analgesia; VAS = verbal analog scale. postoperative analgesic requirement were lower at $30 \mathrm{~mL}$ group. Albrecht and coworkers ${ }^{32}$ found that bilateral TAP block with $30 \mathrm{~mL}$ of $0.25 \%$ bupivacaine with 1:200,000 epinephrine for each side did not provide additional analgesic benefit when added to trocar insertion site local anesthetic infiltration for laparoscopic gastric bypass surgery. But some studies achieved lower VAS scores with 15 to $20 \mathrm{~mL}$ of local anesthetic mixture compared to control groups. ${ }^{12,18,19}$ In a study assessing sensory loss in healthy volunteers, bilateral oblique subcostal TAP block with $20 \mathrm{~mL}$ of $0.375 \%$ ropivacaine effectively blocked T7-T12 dermatomes of the midabdomen. ${ }^{33}$ In the light of this information we assumed that a volume of $30 \mathrm{~mL}$ should be enough for achieving adequate spread of local anesthetic mixture.

We administered a composition of $10 \mathrm{~mL}$ lidocaine $1 \%$, plus $20 \mathrm{~mL}$ bupivacaine $0.125 \%$, total of $30 \mathrm{~mL}$ of local anesthetic mixture for single side TAP block in our study. We chose lidocaine for its fast onset of action to achieve adequate analgesic effect before surgical incision. Reduction in intraoperative fentanyl consumption indicates that we managed to reach this goal. But lidocaine has short duration of analgesia. Median duration of surgery was 180 minutes for Group TAP in our study, and the analgesic efficacy of lidocaine significantly decreases 3 hours after the administration. Using a long-acting local anesthetic like bupivacaine or ropivacaine at maximum safe dose available or additives may be more convenient to achieve longer analgesic effect.

The issue about adequate and effective volume for TAP block is still debatable. The type of surgery, location of incisions, previous abdominal surgeries, patients' anatomic variability, and connections between nerves may be responsible for variable extension of sensory loss after TAP blocks. Detailed studies are needed.

There are several limitations of our study. First, we did not assess the dermatomal levels of sensory loss. Second, the number of female patients is significantly higher in Group TAP. Third, we included both single and multiple access tract cases in our study. More than one access tracts may cause more pain. Even so, there is not a significant difference in the number of multiple access tracts between the groups in our study. Likewise, patients who underwent both subcostal and intercostal access were included in the study. Intercostal access causes more pain than subcostal access. However, there was no statistically significant difference in the intercostal
FIG. 1. Number of patients with VAS scores equal to or higher than 4 . IV $=$ intravenous; TAP = transversus abdominis plane; $\mathrm{VAS}=$ verbal analog scale.

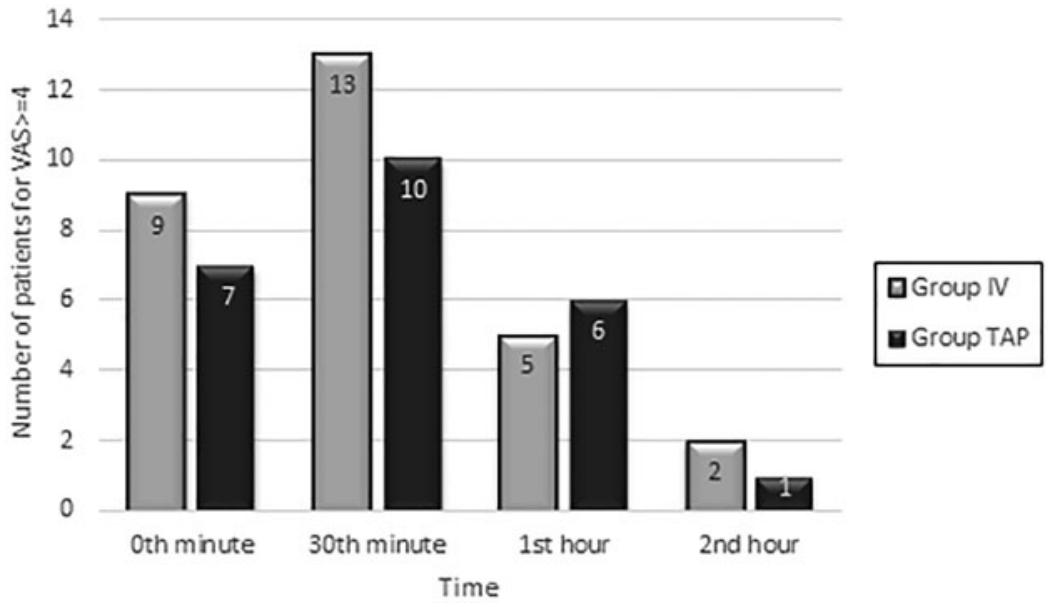


access cases between the two groups. Further studies, excluding multiple access tracts and intercostal access, are needed. In addition, we did not assess the pain scores during physical effort considering that nephrostomy tubes, especially with supracostal punctures, can cause considerable pain on deep breathing. ${ }^{2}$

\section{Conclusions}

Preemptive unilateral ultrasound-guided subcostal TAP block decreases perioperative fentanyl and postoperative total morphine consumption in PCNL patients compared to IV analgesic management.

\section{Acknowledgment}

The authors thank Dr. Sevim Purisa for her valuable contribution for statistical analysis.

\section{Author Disclosure Statement}

No competing financial interests exist.

\section{Funding Information}

No funding was received for this article.

\section{References}

1. Türk C, Petrik A, Sarica K, et al. EAU guidelines on interventional treatment for urolithiasis. Eur Urol 2016;69: 475-482.

2. Borle AP, Chhabra A, Subramaniam R, et al. Analgesic efficacy of paravertebral bupivacaine during percutaneous nephrolithotomy: An observer blinded, randomized controlled trial. J Endourol 2014;28:1085-1090.

3. Ghani KR, Andonian S, Bultitude M, et al. Percutaneous nephrolithotomy: Update, trends, and future directions. Eur Urol 2018;70:382-396.

4. Matlaga BR, Krambeck AE, Lingeman JE, et al. Surgical management of upper urinary tract calculi. In: CampbellWalsh Urology. 11th ed., 2016, pp. 1260-1290.

5. Aravantinos E, Kalogeras N, Stamatiou G, et al. Percutaneous nephrolithotomy under a multimodal analgesia regime. J Endourol 2009;23:853-856.

6. Shahait M, Lee DI. Application of TAP block in laparoscopic urologic surgery: Current status and future directions. Curr Urol Rep 2019;20:20.

7. Rafi A. Abdominal field block: A new approach via the lumbar triangle. Anaesthesia 2001;56:1024-1026.

8. Hebbard P. Subcostal transversus abdominis plane block under ultrasound guidance. Anesth Analg 2008;106:674675.

9. Niraj G, Kelkar A, Jeyapalan I, et al. Comparison of analgesic efficacy of subcostal transversus abdominis plane block with epidural analgesia following upper abdominal surgery. Anaesthesia 2011;66:465-471.

10. Wassef M, Lee DY, Levine JL, et al. Feasibility and analgesic efficacy of the transversus abdominis plane block after single-port laparoscopy in patients having bariatric surgery. J Pain Res 2013;6:837-841.

11. Oksar M, Koyuncu O, Turhanoglu S, et al. Transversus abdominis plane block as a component of multimodal analgesia for laparoscopic cholecystectomy. J Clin Anesth 2016;34:72-78.
12. Chen CK, Tan PCS, Phui VE, et al. A comparison of analgesic between oblique subcostal transversus abdominis plane block and intravenous morphine for laparoscopic cholecystectomy: A prospective randomized controlled trial. Korean J Anesthesiol 2013;64:511-516.

13. Bhatia N, Arora S, Jyotsna W, et al. Comparison of posterior and subcostal approaches to ultrasound-guided transverse abdominis plane block for postoperative analgesia in laparoscopic cholecystectomy. J Clin Anesth 2014; 26:294-299.

14. Chin KJ, McDonnell JG, Carvalho B, et al. Essentials of our current understanding: Abdominal wall blocks. Reg Anesth Pain Med 2017;42:133-183.

15. Hanna MN, Ouanes J-PP, Tomas VG. Regional anesthesia techniques for acute pain management. In: Ballantyne JC, Fishman SM, Rathmell JP, eds. Bonica's Management of Pain. 5th ed., Walters Kluwer, 2019, pp. 2714-2831.

16. Carney J, Finnerty O, Rauf J, et al. Studies on the spread of local anesthetic solution in transversus abdominis plane block. Anaesthesia 2011;66:1023-1030.

17. Suseela I, Anandan K, Aravind A, et al. Comparison of ultrasound-guided bilateral subcostal transversus abdominis plane block and port-site infiltration with bupivacaine in laparoscopic cholecystectomy. Indian J Anaesth 2018;62: 497-501.

18. Basaran B, Basaran A, Kozanhan B, et al. Analgesia and respiratory function after laparoscopic cholecystectomy in patients receiving ultrasound-guided bilateral oblique subcostal transversus abdominis plane block: A randomized double-blind study. Med Sci Monit 2015;21:13041312.

19. Breazu CM, Ciabanu L, Hadade A, et al. The efficacy of oblique subcostal transversus abdominis plane block in laparoscopic cholecystectomy: A prospective, placebo controlled study. Rom J Anaesth Intensive Care 2016;23: $12-18$.

20. Amr Y, Amin S. Comparative study between effect of preversus post-incisional transversus abdominis plane block on acute and chronic post-abdominal hysterectomy pain. Anesth Essays Res 2011;5:77.

21. Choi YM, Byeon GJ, Park SJ, et al. Postoperative analgesic efficacy of single-shot and continuous transversus abdominis plane block after laparoscopic cholecystectomy: A randomized controlled clinical trial. J Clin Anesth 2017;39: 146-151.

22. Baldea KG, Patel PM, Delos Santos G, et al. Paravertebral block for percutaneous nephrolithotomy: A prospective, randomized, double-blind placebo-controlled study. World J Urol 2020 [Epub ahead of print]; DOI: 10.1007/s00345020-03093-3.

23. Tan X, Fu D, Feng W, Zheng X. The analgesic efficacy of paravertebral block for percutaneous nephrolithotomy: A meta-analysis of randomized controlled studies. Medicine (Baltimore) 2019;98:e17967.

24. Kim E, Kwon W, Oh S, Bang S. The erector spinae plane block for postoperative analgesia after percutaneous nephrolithotomy. Chin Med J (Engl) 2018;131:1877-1878.

25. Aydin ME, Ahiskalioglu A, Tekin E, Ozkaya F, Ahiskalioglu EO, Bayramoglu A. Relief of refractory renal colic in emergency department: A novel indication for ultrasound guided erector spinae plane block. Am J Emerg Med 2019; 37:794.e1-794.e3.

26. Gultekin MH, Erdogan A, Akyol F. Evaluation of the efficacy of the erector spinae plane block for postoperative 
pain in patients undergoing percutaneous nephrolithotomy: A randomized controlled trial. J Endourol 2019 [Epub ahead of print]; DOI: 10.1089/end.2019.0777.

27. Ibrahim M, Elnabtity AM. Analgesic efficacy of erector spinae plane block in percutaneous nephrolithotomy: A randomized controlled trial. Anaesthesist 2019;68:755-761.

28. Kılıç E, Bulut E. Quadratus lumborum block III for postoperative pain after percutaneous nephrolithotomy. Turk J Anaesthesiol Reanim 2018;46:272-275.

29. Dam M, Hansen CK, Poulsen TD, et al. Transmuscular quadratus lumborum block for percutaneous nephrolithotomy reduces opioid consumption and speeds ambulation and discharge from hospital: A single centre randomised controlled trial. Br J Anaesth 2019;123:e350-e358.

30. Ökmen K, Ökmen BM. Ultrasound-guided anterior quadratus lumborum block for postoperative pain after percutaneous nephrolithotomy: Randomized controlled trial. Korean J Anesthesiol 2020;73:44-50.

31. Şahin AS, Ay N, Şahbaz NA, et al. Analgesic effect of ultrasound-guided transverse abdominis plane block using different volumes and concentrations of local analgesics after laparoscopic cholecystectomy. J Int Med Res 2017;45: 211-219.

32. Albrecht E, Kirkham KR, Endersby RVW, et al. Ultrasounguided transversus abdominis plane (TAP) block for laparoscopic gastric-bypass surgery: A prospective randomized controlled double-blinded trial. Obes Surg 2013;23:13091314.

33. Chen Y, Shi KJ, Xia Y, et al. Sensory assessment and regression rate of bilateral oblique subcostal transversus abdominis plane block in volunteers. Reg Anesth Pain Med 2018;43:174-179.

Address correspondence to: Aylin Özdilek, MD

Department of Anesthesiology and Reanimation Cerrahpasa Medical Faculty Istanbul University-Cerrahpasa Kocamustafapaşa Cad No 34, Fatih Istanbul 34098

Turkey

E-mail: draylinnizamoglu@yahoo.com

\section{Abbreviations Used}

ASA $=$ American Society of Anesthesiologists

$\mathrm{BMI}=$ body mass index

$\mathrm{ESPB}=$ erector spinae plane block

$\mathrm{SWL}=$ extracorporeal shockwave lithotripsy

$\mathrm{IV}=$ intravenous

PCA $=$ patient-controlled analgesia

$\mathrm{PCNL}=$ percutaneous nephrolithotomy

$\mathrm{PVB}=$ paravertebral block

$\mathrm{QLB}=$ quadratus lumborum block

$\mathrm{SD}=$ standard deviation

$\mathrm{TAP}=$ transversus abdominis plane

VAS $=$ verbal analog scale 